\title{
INFORMATIUN TO USERS
}

This was produced from a copy of a document sent to us for microfilming. While the most advanced technological means to photograph and reproduce this document have been used, the quality is heavily dependent upon the quality of the material submitted.

The following explanation of techniques is provided to help you understand markings or notations which may appear on this reproduction.

1. The sign or "target" for pages apparently lacking from the document photographed is "Missing Page(s)". If it was possible to obtain the missing page(s) or section, they are spliced into the film along with adjacent pages. This may have necessitated cutting through an image and duplicating adjacent pages to assure you of complete continuity.

2. When an image on the film is obliterated with a round black mark it is an indication that the film iispector noticed either blurred copy because of movement during exposure, or duplicate copy. Unless we meant to delete copyrighted materials that should not have been filmed, you will find a good image of the page in the adjacent frame.

3. When a map, drawing or chart, etc., is part of the material being photographed the photographer has followed a definite method in "sectioning" the material. It is customary to begin filming at the upper left hand corner of a large sheet and to continue from left to right in equal sections with small overlaps. If necessary, sectioning is continued again-beginning below' the first row and continuing on until complete.

4. For any illustrations that cannot be reproduced satisfactorily by xerography, photographic prints can be purchased at additional cost and tipped into your xerographic copy. Requests can be made to our Dissertations Customer Services Department.

5. Some pages in any document may have indistinct print. In all cases we have filmed the best available copy.

\section{University \\ Microfilrins International}


AILEN, MELVIN LIOYD

INDIVIDUAL COPULATORY PREFERENCE AND THE "STRANGE FEMALE EFFECT" IN A CAPTIVE GROUP-IIVING MALE CHTMPAINZEE (PAN TROGLODYTES)

The University of Oklahoma

PH.D.

1980

\author{
University \\ Microfilms \\ International 300 N. Zeeb Road, Ann Arbor, MI 48106
}

18 Bedford Row, London WCIR 4EJ, Engiand 
THE UNIVERSITY OF OKLAHOMA

GRADUATE COLLEGE

INDIVIDUAL COPULATORY PREFERENCE AND THE "STRANGE FEMALE EFFECT" IN A CAPTIVE GROUP-LIVING MALE CHIMPANZEE (PAN TROGLODYTES)

\author{
A THESIS \\ SUBMITTED TO THE GRADUATE FACULTY \\ in partial fulfillment of the requirements for the \\ degree of \\ DOCTOR OF PHILOSOPHY
}

By

MELVIN LLOYD ALLEN

Norman, Oklahoma

1980 
INDIVIDUAL COPULATORY PREFERENCE AND THE "STRANGE FEMALE EFFECT" IN A CAPTIVE GROUP-LIVING MALE CHIMPANZEE (PAN TROGLODYTES)

\section{A THESIS}

APPROVED FOR THE DEPARTMENT OF PSYCHOLOGY

By

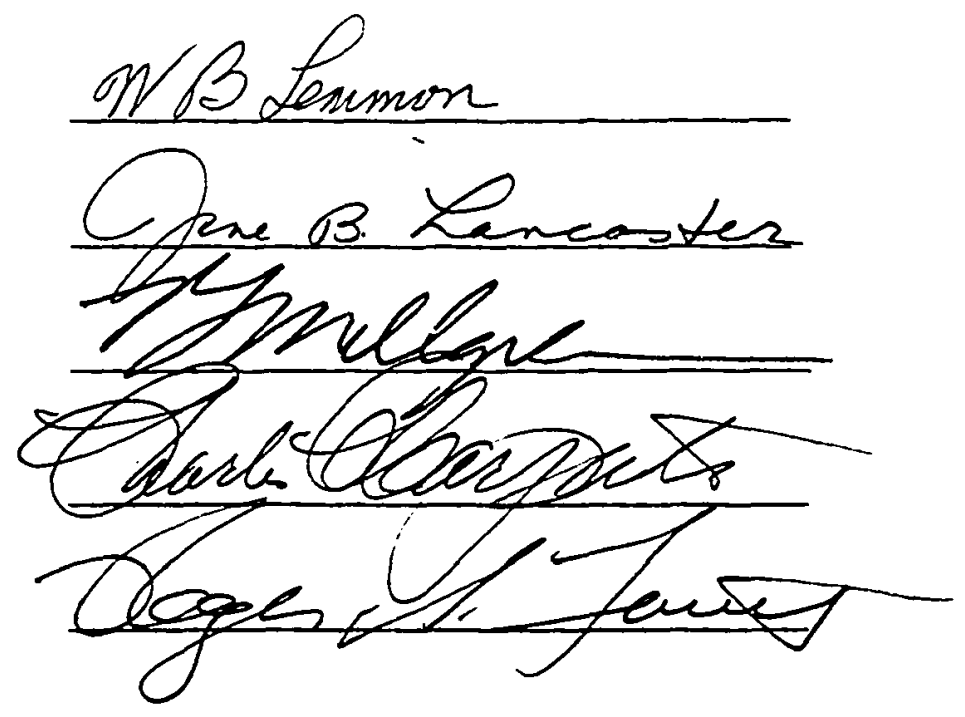




\section{ACKNOWLEDGEMENTS}

I sincerely wish to thank the members of my dissertation committee at the University of Oklahoma, Dr. W. B. Lemmon, Dr. Jane B. Lancaster, Dr. Charles C. Carpenter, Dr. Roger S. Fouts, and Dr. Roger L. Mellgren, for their continued support of my pursuit of an interdisciplinary degree in primatology, and for their encouragement of the writing of this paper. 
ABSTRACT

The common chimpanzee has been considered to be a promiscuous species, although transient consort relationships and male possessive behavior have been described by Tutin (1975, 1979).

A prolific adult male chimpanzee was housed with from 4 to 7 adult female chimpanzees (depending on the females' maternal status) and copulations were recorded from $8 / 7 / 78$ until $2 / 16 / 79$, during morning feeding periods. Ten females composed the fluctuating available partners.

Sixty-four observed copulations involved 6 females. One $\underline{S}$ was clearly preferred, including occasions when she was not maximally tumescent (e.g., completely detumescent, pregnant) and other available females were maximally tumescent. The remainder of the observed copulations, with 1 exception, involved females who had been recently reintroduced into the one-male breeding group. Such copulations took place on and continued temporarily after the day of reintroduction for 2 females, and after the resumption of menstrual cycling for 2 females who had been reintroduced while still lactating. Nonpreferred females were impregnated during the period of data collection, even though copulations with them were not observed.

These data suggest that the male chimpanzee can form an individual mating preference regardless of the hormonal status of his available partners without lessening his reproductive success with nonpreferred 
females, but maximizes his reproductive success by copulating with novel females. 
TABLE OF CONTENTS

\section{Page}

List of Tables................... . vii

List of Figures. . . . . . . . . . . . . . . v viii

Chapter

I. Introduction ............... 1

II. Method ................ . 7

III. Results.................. 11

IV. Discussion ................ 17

References . . . . . . . . . . . . 35 


\section{LIST OF TABLES}

Table

$\underline{\text { Page }}$

I. Information Concerning the Female Chimpanzees. . . . . 25

II. Observed Copulations with Available Females. . . . . 26

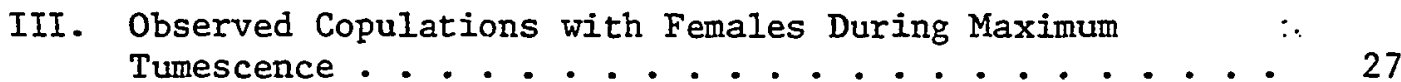

IVa. Observed Copulations Within Pairs of Females of the Same Hormonal (Sexual) Status. . . . . . . . 28

IVb. Observed Copulations Within Pairs of Females of the Same Hormonal (Sexual) Status. . . . . . . . . 29

V. Observed Copulations Within Trios of Females of the Same Hormonal (Sexual) Status. . . . . . . . 30

VI. Observed Copulations Within Pairs of Females Where the Preferred Female was Less Hormonally (Sexually) Attractive than the Nonpreferred Female. . . . . . . 31

VII. Observed Copulations Within Trios of Females Where the Preferred Female was Less Hormonally (Sexually) Attractive than the Nonpreferred Females . . . . . . 32

VIII. Number of Thrusts to Ejaculations by Pan with the Females During Various Levels of Turgidity/Attractiveness. . . 


\section{LIST OF FIGURES}

Figure

Page

I. Observed copulations in complete and partial 10-day blocks . 34

viii 


\section{INDIVIDUAL COPULATORY PREFERENCE AND THE "STRANGE FEMALE EFFECT" IN A CAPTIVE GROUP-LIVING MALE CHIMPANZEE (PAN TROGLODYTES)}

\section{CHAPTER I}

\section{INTRODUCTION}

Reproductive behavior in mammals is influenced by several factors, none of which are mutually exclusive. Three factors which have been successfully used to delineate the control of reproductive behavior are genetic, hormonal, and psychological (Young, 1961). The genotype of each species determines the relative dominance of hormonal vs. psychological influences. The actual expression of these predetermined propensities is manifested in the phenotype as a result of environmental influences on the genetic endowment. It is now widely accepted than an examination of the phylogenetic continuum reveals less influence of hormonal and greater influence of psychological factors on the expression of reproductive interactions as neocortical structures have evolved in particular species. According to this scheme, psychological factors reach their greatest influence in Homo sapiens, although even this species is not completely liberated from hormonal influences (Beach, 1976a). It is clear that experience greatly affects sexual behavior in humans (Ford and Beach, 1951; Kinsey et al, 1953; Money et al., 1957). Among the primates, only the reproductive behavior of man is considered to be determined more by psychological than 
by endocrine factors, including even the "higher primates" such as the rhesus monkey (Michael et al., 1972). This view places man alone among all mammals, even very closely related species such as the chimpanzee, as the only species whose reproductive behavior (i.e., copulation) is more under psychological than hormonal control.

An important determinant of when copulation is performed has been described by Beach (1976b) as female attractivity, which he defines as "the female's stimulus value in evoking sexual responses by the male" (p. 105). He further delineated three categories of stimuli which form the basis of female attractivity: nonbehavioral stimuli, behavioral stimuli, and nonhormonal factors.

Nonbehavioral stimuli which attract the male include visual cues such as the sexual swelling of some primates (Wickler, 1967, Saayman, 1972; McGinnis, 1973), and chemical stimuli such that emanate from vaginal secretions (Michael et al., 1971; Hess, 1973; McGinnis, 1973) affecting the olfactory and gustatory receptors of the male. Behavioral stimuli which serve to attract the male include solicitation, invitation or presentation (Dixson et al., 1973; McGinnis, 1973), behaviors which Beach (1976b) subsumes under proceptivity (i.e., behavior consisting of appetitive activities displayed by females in response to stimuli emanating from males). The above stimuli are known to be directly influenced by fluctuating gonadal, and to a lesser extent, by some adrenal hormones.

Several investigators of primate sexual behavior have demonstrated that female attractivity (as measured by frequency of copulation) reaches its maximum just before and up to spontaneous ovulation, when the levels of the estrogens are highest (e.g., rhesus monkey, Michael et al., 1968; 
pigtail monkey, Eaton and Resko, 1974; hamadryas baboon, Kummer, 1971; chimpanzee, Lemmon and Allen, 1978) or after exogenous estrogenic stimulation (e.g., rhesus monkey, Phoenix, 1973; chacma baboon, Saayman, 1970; chimpanzee, Young and Orbison, 1944). Estrogen induced increases in attractivity during the follicular phase are diminished during the luteal phase as a result of the inhibiting effect of progesterone (Ball, 1941; Saayman, 1972; Eaton and Resko, 1974). Whetiner estrogen or androgen is the hormone responsible for proceptivity in primates is unclear, since exogenous androgen may be converted to estrogen before behavior is affected (Beach, 1976b). Both these hormones peak during the preovulatory phase of the menstrual cycle coincident to maximum tumescence in the chimpanzee (Graham et al., 1972; Graham, 1976, Hobson, et al., 1976) and Money (1961) has claimed that testosterone is the libido hormone in women. Whichever homone is found responsible for proceptivity (if both are not), the occurrence of their highest levels are simultaneous, therefore, allowing at least a temporal if not a hormone-specific measure of their influence on proceptivity, and, concomitantiy on attractivity.

Nonhormonal fartuss winch influence attractivity are apparent when individuals display copulatory preferences for particular partners. Such preferences have been reported to be a common phenomenon in the sexual interactions of numerous primate species. The preferences of interest here are male preferences for particular females.

Rowell (1963) reported that two rhesus monkey males (Macaca mulatta) had "favourite wives" which maintained their position as favorites almost continuously through the menstrual cycle. Herbert (1968) found that one of two ovariectomized thesus monkeys was markedly preferred when both were 
either given the same dose of estrogen or left untreated. Everitt and Herbert (1969) manipulated the hormonal status of ovariectomized thesus monkeys and discovered that the males displayed a clear preference for one female of the two when both were given the same levels of estradiol. This preference was decreased by either the withdrawal of estrogen from the favored partner, or by administering her 25 mg progesterone, but not reversed. Treating the sceierred female with both $5 \mu \mathrm{g}$ estradiol and $5 \mathrm{mg}$ progesterone per day had a lesser but similar effect. Perachio et al. (1973) also found that preference or favoritism significantly affected the spontaneous sexual behavior of rhesus monkeys. Agar and Mitchell (1975) reviewed the field investigations of rhesus monkeys and wrote that males prefer particular partners. Herbert (1978, p. 472) concluded that in the rhesus monkey "a female's attractiveness depends upon several qualities in her, including those determining the preference of a male for a particular kind of female."

Stephenson (1974) demonstrated mating preferences which ran across social class lines in the free-ranging Japanese macaque (Macaca fuscata). Higher class females were preferred by higher class males, and lower class females were preferred by lower class males. Enomoto (1978) found that in Japanese macaques both sexes showed a tendency to choose only a few of the available partners of the opposite sex as sexual partners. Wolfe's (1979) data reportedly indicate some partner preferences in copulation among Japanese macaques Iiving in a field enclosure.

Goldfoot (1971) studied the pigtail macaque (Macaca nemestrina) in the laboratory and found that when three feinales were simultaneously in the same ovarian condition, one was preferred. Furthermore, wher the 
least favored was the only one of the available females in the follicular phase, she was still not chosen as a mating partner.

Saayman (1970) and Hausfater (1975) described personal favoritism of males for particular females in feral baboons (Papio ursinus and Papio cynocephalus, respectively).

Slob et al. (1978a) reported partner preferences by male stumptail macaques (Macaca arctoides) housed with trios of females, a phenomenon which persisted after implantation of progesterone. Slob et al. (1978b) pointed out that nonhormonal factors are related to the heterosexual interactions of this species of macaque.

Early studies of the chimpanzee (Pan troglodytes) described no partner preferences (Kortlandt, 1962; Goodall, 1965; Nishida, 1968). Van Lawick-Goodall (1975) reported subsequently, however, that a male chimpanzee may form a consortship with the same female during successive estrous periods, and that consortships may be formed with infertile females. Tutin (1975) found that of fourteen wild male chimpanzees only one displayed no partner preferences. Tutin (1979, p. 32) reported the following regarding chimpanzee copulatory behavior: "The data indicate that while opportunistic mating is not overtly competitive, individual and general preferences do exist, and so this mating pattern should not be described as totally indiscriminative."

Partner preferences obviously exist among male cercopithecids ar. 3 pongids. The studies cited above point to the fact that nonhormonal factors influence the choice of a mating partner. It remains unknown, however, if nonhormonal factors can overcome hormonal influences on the attractivity of a female primate other than the human. The purpose of the 
present study was to determine whether a group-living male chimpanzee can display copulatory preferences based on nonhormonal characteristics of the preferred partners, not only when other available partners are similarly hormonally attractive, but even when other available partners are highly hormonally attractive and the preferred partners are not. 


\section{CHAPTER II}

METHOD

\section{Subjects}

Eleven adult chimpanzees (Pan troglodytes) were used as subjects, one male, Pan, and ten females, Carrie, Thelma, Mona, Carolyn, Sally, Peggy, Pampy, Wendy, Cindy and Candy. Table I provides information concerning the females during the period of data collection: dominance among the females themselves, age, familiarity with the male, and parity. Pan reached 18 years of age during the period of data collection and has sired over 40 progeny. All the chimpanzees are reported to be wild born except Pampy, Mona and Candy. Pampy is captive born. Whether Mona and Candy are captive or wild born has not been confirmed by the parties from whom they were obtained.

\section{Laboratory Environment}

The chimpanzees were housed at the Institute for Primate Studies, located in Norman, Oklahoma and owned by the director, Dr. W. B. Lemmon. A $1600 \mathrm{ft}^{2}$ laboratory housed the chimpanzees used in this study together with other chimpanzees of all maturational levels and both sexes. The laboratory contains several adjustable compartments in which particular chimpanzees can be segregated bodily into separate groups. During this study there were from 4 to 5 separate areas at any one time. Two groups involved the chimpanzees used for data collection, a breeding group and 
a maternity group. A parturition compartment was provided when necessary. The laboratory provides continuous water, controlled temperature, access to outside enclosures, and avenues for escape from conspecifics. Appropriately sturdy swings and automobile tires are available but most overt behavior is social. The breeding group had from 5 to 6 separate compartments to their access during the study. The maternity group had from 1 to 3 , one of which was always one of the two largest areas in the laboratory.

\section{Procedure}

Females who were no more than an estimated 160 days pregnant or who were not nursing an infant were housed with Pan. Females who were estimated to be in their third trimester of pregnancy or who had a suckling infant were housed together, but contributed data while with Pan at some time during the study. Females who were suspected of imminent birth were temporarily segregated individually until parturition and it was clear that the neonate was healthy and receiving appropriate maternal care. The mother and infant were then housed with the other mother-infant pairs. Copulations were recorded only from females who were housed with Pan in the breeding group. Other copulations were not considered in this study. The sexual swelling of each female was also recorded regardless of the group with which she was housed.

Copulations were recorded during daily morning feeding periods beginning about 8:00 A.M. and usually requiring approximately one hour to complete from $8 / 7 / 78$ to $2 / 16 / 79$. Copulations during the day are concentrated during the early morning, both in the wild (Tutin and McGinnis, in press) 
and in captivity (personal observation). Data were not collected on the weekends. This procedure of data collection is neither random nor representative of all the copulations Pan participated in during the study period.

The level of turgescence of the anogenitai region was recorded daily for each individual female. Swellings were categorized into one of three classifications: 1 representing no swelling, 2 representing intermediate swelling, and 3 representing maximum swelling. Graham (1970, 1973, 1976), Graham et al. (1972) and Hobson et al. (1976) have thoroughly demonstrated that the cyclical tumescence of the female chimpanzee's anogenital area is a reliable indicator of their underlying reproductive hormonal condition. The following sexual states were determined from the levels of swelling and parturition dates: complete detumescence, tumescence, maximum tumescence, detumescence, pregnancy with no swelling, pregnancy with intermediate swelling, pregnancy with maximum swelling, lactation and postpartum acyclicity.

Copulations were observed by visual inspection and timed with a stop watch. A copulation began upon intromission and ended with the dismount after ejaculation. Criteria for ejaculation included observable rhythmic contraction of the anal sphincter, presence of coagulated semen protruding from or taken by the male from the urethral meatus immediately after dismounting, or both. Besides the female with whom Pan copulated, several other measures were taken: identification of the immediate initiator of copulation, the behaviors (i.e., bodily postures and gestures, facial expressions, vocalizations) displayed by the initiator of copulation, the behaviors displayed in reaction to initiation of copulation, facial 
expressions and vocalizations displayed during copulation, and the number of thrusts performed to reach ejaculation.

Data were analyzed partially by means of statistical methods in Hays (1973). 


\section{CHAPTER III}

\section{RESULTS}

Ninety-two intromissions with thrusting were observed. Sixtyfour of these resulted in ejacclations (i.e., 64 copulations were observed). Thelma accounted for 19 nonejaculatory mounts (range 1-6), Wendy was involved in 6 nonejaculatory mounts (range 1-2), Pampy received 2 nonejaculatory mounts during separate sessions, and Cindy was mounted once without ejaculation. These nonejaculatory mounts, with one exception, were followed by an ejaculatory mount, always involving the same female. In only one instance was a nonejaculatory mount not followed by an ejaculatory mount during a single observational period. This involved Thelma. Twelve nonejaculatory mounts occurred during complete detumescence, 13 were observed during maximum tumescence, and 3 occurred during detumescence.

Except for 2 mornings, only one ejaculation was observed per session. On one occasion, 3 separate sexual cycles were observed with Pan and Thelma when she was completely detumescent. The interval between these successive ejaculations was approximately 5 minutes. On only one occasion, was Pan observed to copulate with more than one female during a single session. This occurred with Pampy at maximum tumescence, followed by Thelma at complete detumescence. The interval between the ejaculation with Pampy and Thelma was about 7 minutes. The ejaculation with Thelma was preceded by 6 separate intromissions with thrusting. 
The females were available to Pan for different numbers of days. The number of copulations per day of availability for the females showed significant preferences $\left(\mathrm{X}^{2}=73.57\right.$, df $\left.=8, \mathrm{p}<.001\right)$. See Table II.

Copulations generally occur more frequently during maximum tumescence than during any other sexual state. Not all females were available to Pan for the same number of days at maximum tumescence. The number of copulations per day of availability for the females during maximum tumescence show significant preferences $\left(x^{2}=24.31\right.$, df $\left.=7, p<.005\right)$. See Table III.

Tables II and III list copulations with females only on an individual basis. The analyses do not consider whether two or more females were simultaneously available at the same, less or more attractive hormonal state. The number of observed copulations between pairs or among trios of females who were simultaneously at the same hormonal state show significant preferences (for pairs, $x^{2}$ ranges from 4-7, df $=1$, $p$ ranges from $<.01-<.05$; for trios, $\mathrm{x}^{2}=8$, df $=2$, $\left.\mathrm{p}<.025\right)$. All possible pairs and trios did not obtain, although Thelma, Wendy and Pampy were the only females to be significantly preferred for those observed. Carolyn, Peggy and Sally were invariably nonpreferred no matter which female or females displayed the same hormonal condition with them. When Thelma and Pampy displayed the same sexual state, while either in a pair or in a trio, Thelma was significantly preferred. See Tables IVa, $b$ and V.

Tables VI and VII display observed copulations with females in pairs or trios, where the preferred female was actually in a less hormonally attractive state than the nonpreferred females (e.g., completely detumescent vs. maximally tumescent, pregnant with no swelling vs. maximally tumescent). All possible pairs and trios were not observed, but 
the significant differences occurred with Thelma in a pair $\left(x^{2}=8\right.$, $d f=1, p<.005)$, and with Thelma and Wendy in trios $\left(x^{2}=6, d f=2\right.$, $p(.05)$. The significantly nonpreferred females in a pair or in a trio were Carolyn, Peggy and Pampy.

According to Beach (1976b), characteristics of the vagina contribute to attractivity. A comparison of the number of thrusts performed by Pan to attain ejaculation with Theima during complete detumescence and maximum tumescence were significantly different (Aspin-Welch $t=2.47$, $\mathrm{df}=13.17, p<.025$, one-tailed). More thrusts were required during complete detumescence as compared to maximum tumescence. A comparison of the number of thrusts performed by $\operatorname{Pan}$ to attain ejaculation with wendy during intermediate swelling and maximum tumescence were not significantly different (Aspin-Welch $t=0.55, \mathrm{df}=3.79$, one-tailed). A comparison of the number of thrusts performed by $P a n$ to attain ejaculation with Thelma, Pampy and Wendy during maximum tumescence were not significantly different $\left(F_{2,22}=0.26\right)$. See Table VIII.

Figure 1 graphically displays the observed copulations in 10-day blocks for the females chosen or accepted as mating partners except Carrie. Carrie was observed to copulate only once during the period of data collection and was excluded from this particular analysis. Some of the blocks are incomplete because of the unavailability of some females during the study period. Notice that Pan's preference for Theina was invariably interruptedimediately upon or shortly after the reintroduction of another female into the breeding group. Wendy and Sally were chosen as copulatory partners immediately upon reintroduction. Wendy was reintroduced while still lactating. Sally was mistakenly diagnosed as being pregnant and 
placed in the maternity group. She was reintroduced into the breeding group during maximum tumescence. Pampy and Cindy were reintroduced while still lactating, but began copulation upon the resumption of menstrual cycling. Pampy solicited the first observed copulation with Pan and another one a week later. The copulations with the other females upon reintroduction were all solicited by Pan. Sally was not observed to copulate with Pan during her availability at the beginning of the study, although she did upon reintroduction. The females began copulating and continued to copulate after reintroduction for differing numbers of days, but all reintroduced females invariably copulated after reintroduction. The immediate initiator of either copulation or a nonejaculatory mount was not always observed, but Pan initiated $80(93.02 \%)$ of those for which a determination was made. Of the females, only Thelma and Pampy were observed to initiate copulation. Thelma initiated $4(4.65 \%), 3$ while maximally tumescent and 1 during complete detumescence. Pampy initiated 2 (2.33\%), both during maximum tumescence. The copulation Thelma initiated during complete detumescence was preceded by 2 complete copulations on the same morning. All female initiated copulations resulted in ejaculation.

The behavior used by the females to initiate copulation was always presentation, and $\mathrm{Pan}$ invariably responded to this solicitation by mounting. Pan displayed 7 behaviors or combinations of behaviors to initiate copulation. He used position on 57 occasions with Thelma, Wendy, Pampy, Sally, Cindy and Carrie. Positioning involves placing the female, who is not at the time in the presentation posture, into the presentation posture. It is a cooperative interaction, not a forceful one. Pan used genital 
display, where the erect penis is shown to the female, on 17 occasions toward Pampy, Thelma, Wendy and Cindy. Genital display with arm wave $(n=2)$, genital display with hand clap $(n=1)$, genital display with extend arm $(n=1)$, wave toward self $(n=1)$, and the insertion of the index finger followed by digital thrusting $(n=1)$ were all used toward Thelma to initiate copulation. Male chimpanzee masturbation of a female chimpanzee has not been previously reported. Neither the females nor Pan displayed any facial expressions or vocalizations during initiation of copulation by themselves.

The response of the females to the initiation of copulation by Pan was induced present $(n=78)$ during $97.5 \%$ of the solicitations. No facial expressions or vocalizations accompanied this response. Carrie displayed withdraw accompanied by full closed grin and scream while at maximum tumescence in reaction to one of Pan's solicitations, but did not try to escape the male when he followed her. The subsequent mount resulted in ejaculation. On one occasion, Thelma's response to Pan's initiation of copulation was withdraw accompanied by scream during complete detumescence, although Pan succeeded in following her and subsequently copulated to completion. During pregnancy with no tumescence, Thelma displayed low open grin with scream and low closed grin with soft squeal in response to 2 of Pan's solicitations, but received him both times. The mounting following low open grin with scream resulted in ejaculation, but the mounting following low closed grin with soft squeal did not. During pregnancy with maximum tumescence, Thelma reacted to 2 of Pan's invitations by emitting full open grin with scream and pout face followed by pant grunt and, again, received him. Neither of the subsequent mountings resulted in 
ejaculation. Cindy emitted full closed grin and squeal in response to a solicitation by Pan during tumescence, but received him for a complete copulation. Wendy displayed full closed grin and scream during maximum tumescence in response to Pan's solicitation, but received him and the subsequent mounting was ejaculatory.

Pan was only observed to display three facial expressions in copulo, low closed grin and full open grin (twice), but no vocalizations. The low closed grin was expressed with Wendy during tumescence and accompanied a complete copulation. The full open grins were displayed while with Thelma during pregnancy with no tumescence and the accompanied mountings were nonejaculatory. Both these instances were involved in a series of nonejaculatory mounts, followed, however, by a complete copulation. Carrie displayed low open grin with copulatory pant during a complete copulation while at maximum tumescence. Thelma displayed low open grin with squeal during a complete copulation after three previous nonejaculatory mounts. She displayed full open grin with squeal during pregnancy with maximum tumescence and Pan did not ejaculate during this mount. Pampy was observed to emit low open grin with squeal and squeal during two complete copulations while maximally tumescent. Wendy emitted soft squeal at tumescence during a complete copulation. She emitted squeal during two successive mounts during maximum tumescence, the first of which accompanied a nonejaculatory mount, the second accompanying a complete copulation. During tumescence, Wendy emitted squeal during an incomplete copulation. She displayed low open grin with scream while lactating during a complete copulation. Sally displayed low open grin and full open grin with squeal while maximally tumescent during two complete copulations. 
CHAPTER IV

\section{DISCUSSION}

Individual copulatory preferences were found for all six measures taken. Perhaps the most remarkable finding of these was that a particular female could be chosen over another or other females who were simultaneously available, even when the preferred female was in a sexual state (representing an underlying hormonal condition) which contributes less to attractivity than the sexual state which the nonpreferred female or females were displaying. This result demonstrates that psychological factors can influence male chimpanzee copulatory partner choice more than do hormonal conditions of the female.

Humans are on the liberated side of the continuum representing hormonal as contrasted to cognitive control of sexuality. That is, if complete hormonal control were represented on the left of the continuum and complete cognitive control vere represented on the right, Homo sapiens would be placed on the right side. An actual interval or ratio scale of measurement which indicates just how far to the right of center our species lies has not been determined, although humans are considered to be further to the right than any other species. Although nonhormonal factors influencing heterosexual interactions have been reported, no nonhuman primate species is generally considered to be affected more by nonhormonal than by hormonal factors. If the data collected in this study are found to be generally true of the propensity for nonhormonal factors to be of a 
greater influence on copulatory partner choice, then chimpanzees should be considered on the liberated side of the continuum which indicates relatively greater nonhormonal vs. hormonal control of sexuality, alongside humans.

It is not suggested that the male chimpanzee in this study is manifesting a propensity toward the formation of monogamous ties by showing individual copulatory preferences for infertile females, since in this study it was demonstrated that individual preferences were not exclusive.

It must be stressed that captivity provides much more time between the sexes than is realized in nature. Wrangham (1979) described the geographical social structure of the chimpanzee as being composed of a band or bands of adult males in a territory within which are adult females with their dependent offspring living in microterritories. Individuals other than banded males, mothers and dependent offspring exist (e.g., nulliparous females, females without dependent offspring, emigrant females), but these subgroups describe the most common types. All chimpanzees within a community are familiar with each other, but propinquities between adult males and females are not realized nearly as often as they were in this study. The adult males generally travel together either while patrolling the borders of the community to detect and thwart intrusions from extracommunity conspecifics, while themselves intruding on the territory of extracommunity conspecifies, while foraging, or while cooperatively hunting. They do not normally associate with females unless one is maximally tumescent or an abundant food source draws them together. Such associations would likely prove to be maladaptive. What the data in the present study suggest is that there is a capacity for the male chimpanzee 
to prefer (but not exclusively) a female who is infertile when the environmental conditions allow continual association between the sexes. They also suggest that the male chimpanzee could prefer a female who is infertile if the socioecological conditions were such that such behavior would be adaptive. The socioecological conditions of the extant chimpanzee seem to preclude extended adult male-adult female contact in nature, unless conception is likely to occur.

Lancaster (1979, p. 65) wrote that "most investigators have stressed that personal preferences work against the priority-of-access model because preferences tend to leave young, immature, low-status females or particular subsets of females free to mate with other males." Pan's reproductive success was not debilitated, since even the two least preferred females (Carolyn and Peggy) became pregnant during the period of data collection. The correlation between parity and individual copulatory preference for the subjects during data collection was not significant $\left(r_{x y}=.021\right)$. It seems that, even though all copulations during the period of data collection were not observed, Pan simply preferred to copulate with particular females (mostly Thelma), but still copulated with nompreferred females probably when they were maximally hormonally attractive or perhaps in response to proceptive behavior by them, or both. No copulations were observed for Mona (already pregnant at the start of the study), Peggy or Carolyn, so it is unknown just what circumstances were involved in their matings with Pan. of course, it is impossible to test the priority-of-access model, with the results of this study, since Pan did not have to avoid other male chimpanzees by establishing a consortship, he did not have to compete with other males for available 
females, and he did not have to abandon the other females in the breeding group when he copulated with a particular female. It seems doubtful, but as yet unknown, whether a dominant male in nature, capable of successfully monopolizing available females, would manifest the capacities demonstrated by Pan in captivity. Perhaps not until pair restricted mating and high male parental investment became adaptive in the hominid line, were the preferences for infertile females (who were sometimes fertile) selected.

It was found that, with Thelma, ejaculation was elicited after fewer pelvic thrusts during maximum tumescence than during complete detumescence, but no significant differences between the number of thrusts to ejaculation were found with Wendy during tumescence or detumescence as compared to during maximum tumescence. This suggests that characteristics of the female vagina may be affected by the fluctuating levels of the circulating estrogens, since these are lowest during periods of complete detumescence and are present at higher levels during the follicular, preovulatory and secretory phases of the chimpanzee menstrual cycle. The presence of estrogen may lower the threshold for female chimpanzees' vasocongestive reaction of the perivaginal musculature, the constriction of the vaginal lumen, and the rhythmic contraction of the perivaginal muscles (Allen and Lemmon, in prep.), thus stimulating the male to ejaculate sooner than when this threshold is higher. That this threshold seems not to be significantly different during maximum tumescence as compared to during intermediate swelling may mean that the ejaculatory threshold is not lowered in the male when the female is maximally hormonally attractive, but that the lowered number of thrusts to 
threshold are influenced by the female herself and not merely by the male's willingness to copulate with her. This hypothesis is further substantiated by the fact that Pan's number of thrusts to ejaculation did not significantly differ among Thelma, Wendy and Pampy when they were all maximally tumescent, even though these females' general attractivity (as measured by frequency of copulation individually, in pairs and in trios) was different.

Lemmon and Allen (1978) suggested that the increased frequency of copulation in captive chimpanzees peaked during maximum tumescence perhaps on account of the increased proceptivity correlated with this sexual state. This hypothesis was not supported by the data of this study, since only four female initiated copulations were observed during maximum tumescence and 26 male initiated copulations were observed when females were in this state. This finding may mean that because of Pan's assertiveness the females were not required to solicit copulation. Copulations during this sexual state may have been initiated by Pan because of the females' hormonal attractiveness, not because of attractiveness as a result of saliency due to sexual soliciting. Perhaps proceptivity does largely contribute to maximum frequencies of copulation during maximum tumescence when the males are not as assertive as Pan.

Female vocalizations occurred during both ejaculatory and nonejaculatory mounts. Fox and Fox (1971) proposed that the emission of sound may provide an index of orgasm in nonhuman mammalian species. If this is so, then female orgasm in the chimpanzee sometimes fails to elicit male ejaculation, or vocalizations are emitted by female chimpanzees during copulation which do not accompany the orgasmic response. 
Reintroduced females were invariably chosen as copulatory partners after they were placed back into the breeding group, even if before their separation they were not chosen as mating partners. The above statement does not hold for Candy, who was introduced into the breeding group for the first time on the last day of this study. Pan solicited copulation on that day and has on several occasions since then, but Candy has yet to cooperate at this writing (over a year since the last day of data collection). Candy was captive reared and may not have learned the appropriate behaviors involved in mating. Pusey (1979) reported that it is the females of a natal community who transfer between communities, and they are usually copulated with upon entry or re-entry. This "strange female effect" does not appear to require absolute novelty, but seems only to require an undetermined time of absence. Slob et al. (1978b) also reported that separation and reunion may stimulate copulation in the stumptail macaque. Considering that Sally was not observed to copulate during the period of data collection when she had already been housed with Pan for some time, but that she was immediately upon reintroduction after separation, suggests that intermittent removal from and reintroduction with males may increase the success of breeding colonies' efforts to maximize reproduction. The "strange female effect" is not synonomous with the "Coolidge effect," since Pan was active in mating with other available females before copulations with reintroduced females occurred. This "strange female effect" may still influence the behavior of human males.

Several investigators have attempted to find correlations between individual copulatory preference and nonhormonal characteristics of the preferred females. Perachio et al. (1973) reported that under remotely 
controlled hypothalamic stimulation partner choice was influenced partially by dominance of female rhesus monkeys. Rowell (1963), however, found that the favored status of female rhesus monkeys was not related to rank. Goldfoot (1971) wrote that high rank in female pigtail macaques was important in the determination of mating partners. Membership of a female in a particular lineage was reportedly responsible for choice in mating in Japanese macaques (Enomoto, 1974). Stephenson (1975) found that in Japanese macaques higher class males prefer to copulate with higher class females and lower class males prefer to copulate with lower class females. Tutin (1975) reported that in chimpanzees parous females were involved in more possessive behavior by male suitors and are participants in more consortships than are nulliparous females. Tutin (1979) later implied that individual copulatory preferences in chimpanzees are based on the vicissitudes of interindividual experiences between potential mating partners. Coe et. al. (1979) found that sexual partner choice was inversely related to the degree of familiarity among chimpanzees in a spacious field enclosure. Correlations were examined between the individual copulatory preference data from this study and four characteristics of the females who contributed data: dominance, age, familiarity with Pan, and parity. The parity data involve parturitions of offspring sired by Pan. The female characteristics are listed in Table I. The following correlations were obtained: dominance $\left(r_{x y}=-.041, n s\right)$, age $\left(r_{x y}=-.402, n s\right)$, familiarity $\left(r_{x y}=.123, n s\right)$ and parity $\left(r_{x y}=.021, n s\right)$. Undiscovered personal attributes of the preferred females (particularly Thelma) contributed to the individual copulatory preferences manifested in this study. A discovery of the 
nonhormonal factors besides the effect of novelty responsible for individual copulatory preference in our closest extant relative may disclose interesting and possibly important processes applicable to our species. 
TABLE I

INFORMATION CONCERNING THE FEMALE CHIMPANZEES

\begin{tabular}{|c|c|c|c|c|}
\hline & Dominance ${ }^{1}$ & Age (years) & Familiarity ${ }^{2}$ & Parity ${ }^{3}$ \\
\hline Carrie & 8 th & 15.8 & 13.8 & 3 \\
\hline Thelma & 5 th & 11.1 & 9.1 & 3 \\
\hline Mona & 2nd & 18.7 & 8.7 & 3 \\
\hline Carolyn & 1st & 23.8 & 11.8 & 7 \\
\hline Sally & $6 t h$ & 11.9 & 4.9 & 0 \\
\hline Peggy & 9 th & 14.2 & 10.2 & 1 \\
\hline Pampy & $3 r d$ & 20.2 & 12.2 & 4 \\
\hline Wendy & 4 th & 17.8 & 15.8 & 4 \\
\hline Cindy & 7 th & 12.1 & 9.1 & 2 \\
\hline Candy ${ }^{4}$ & & 7.3 & & \\
\hline
\end{tabular}

${ }^{1}$ Dominance was determined by priority of access to fruits and vegetables 2 Familiarity with the male, Pan

3 The birth of twins was considered as a single parturition $(n=4)$

${ }^{4}$ Candy was housed with Pan during only one day and she had not had access to all the other females listed above at the time of the study 
TABLE II

OBSERVED COPULATIONS WITH AVAILABLE FEMALES

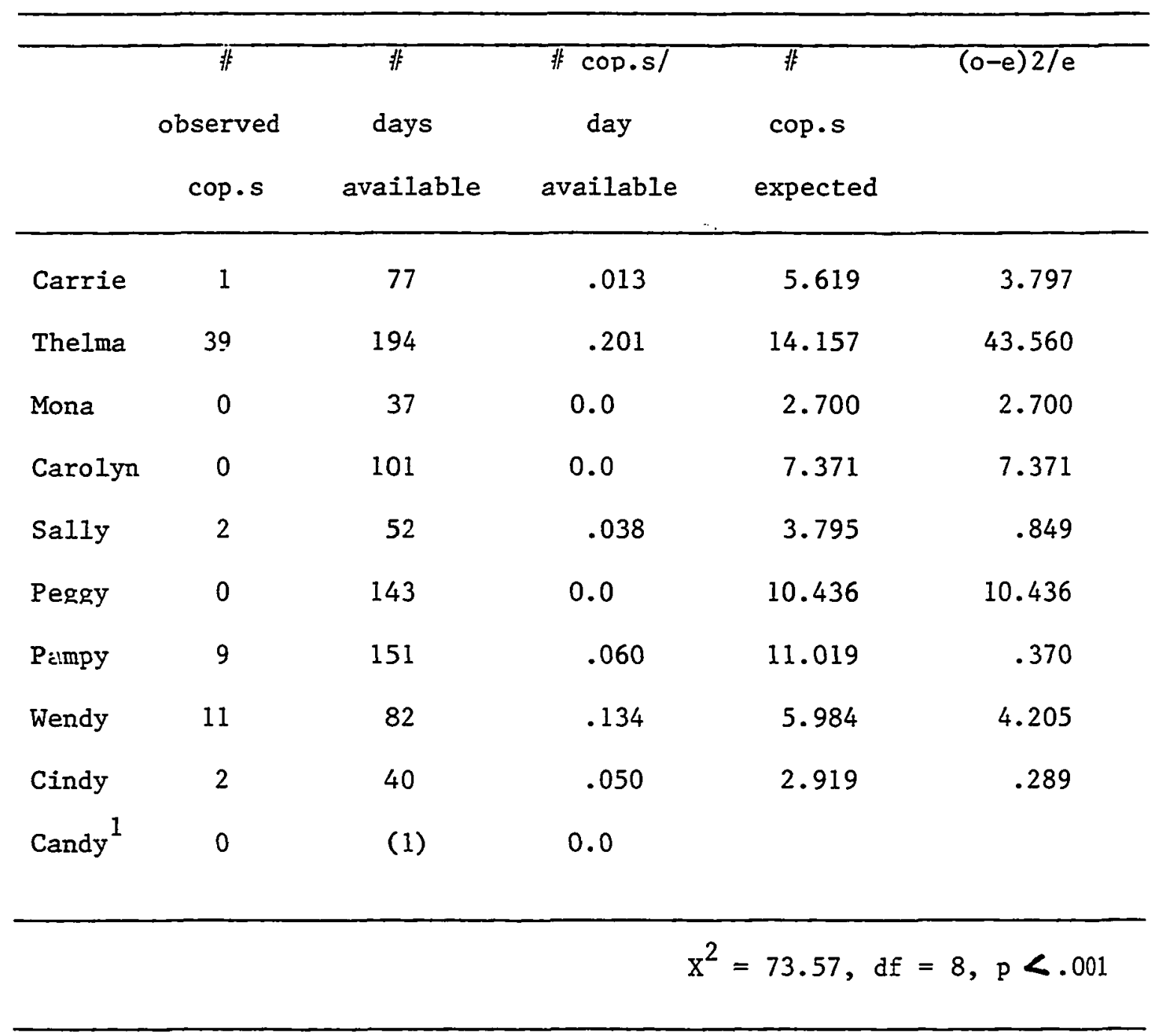

${ }^{1}$ Candy's datum was excluded from the analysis 
TABLE III

OBSERVED COPULATIONS WITH FEMALES DURING MAXIMUM TUMESCENCE

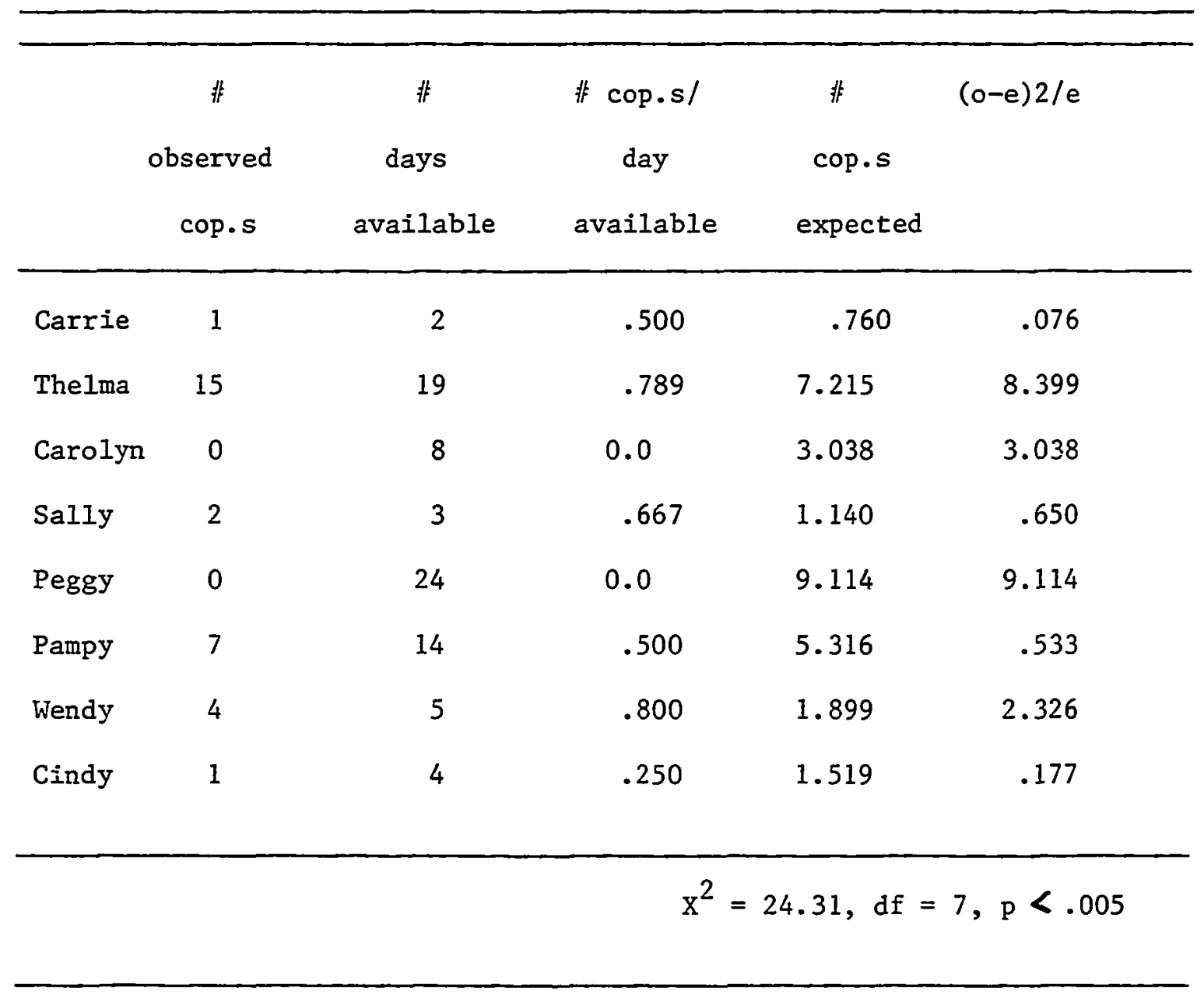


TABLE IVa

OBSERVED COPULATIONS WITHIN PAIRS OF FEMALES

OF THE SAME HORMONAL (SEXUAL) STATUS

Number of Times Preferred

Carrie Thelma Mona Carolyn Sally Peggy Pampy Wendy Cindy Total

Carrie

Thelma

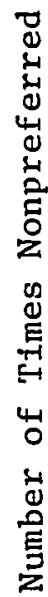

Mona

Carolyn

$\begin{array}{lll}7 & 1 & 8\end{array}$

Sally

6

6

Peggy 7

4

11

Pampy

5

5

Wendy

Cindy

2

2

Total

18

2

47

1 
TABLE IVb

OBSERVED COPULATIONS WITHIN PAIRS OF FEMALES

OF THE SAME HORMONAL (SEXUAL) STATUS

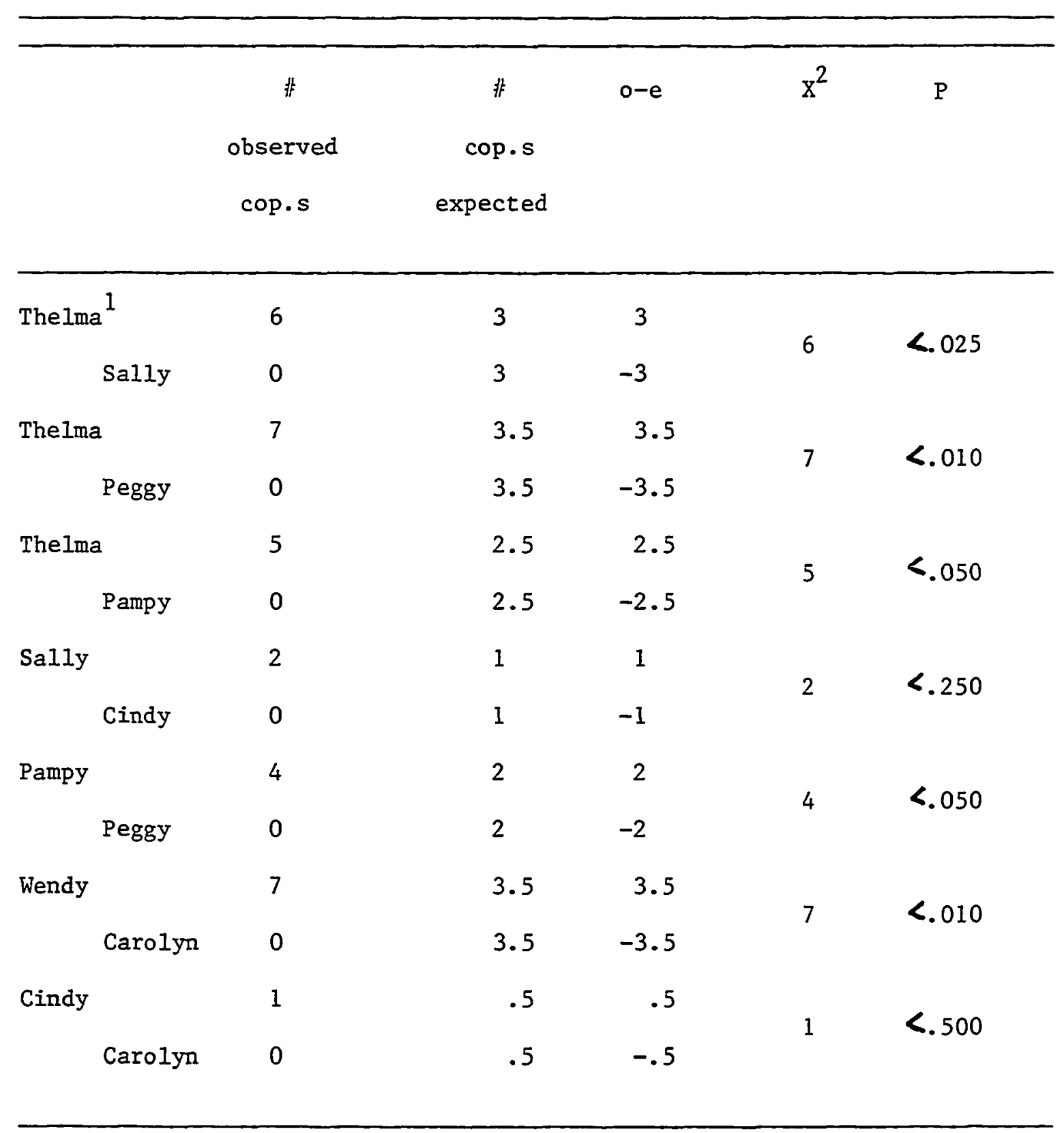

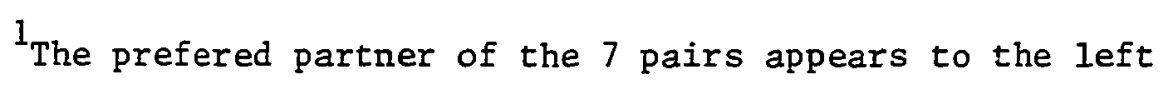


TABLE V

OBSERVED COPULATIONS WITHIN TRIOS OF FEMALES

OF THE SAME HORMONAL (SEXUAL) STATUS

\begin{tabular}{|c|c|c|c|c|c|c|}
\hline $\begin{array}{l}\text { Preferred } \\
\text { female }\end{array}$ & $\begin{array}{l}\text { non- } \\
\text { preferred } \\
\text { female }\end{array}$ & $\begin{array}{c}\# \\
\text { observed } \\
\text { cop.s }\end{array}$ & $\begin{array}{c}\# \\
\text { cop.s } \\
\text { expected }\end{array}$ & o-e & $x^{2}$ & $\mathrm{P}$ \\
\hline \multirow[t]{3}{*}{ Thelma } & & 4 & 1.33 & 2.67 & & \\
\hline & Sally & 0 & 1.33 & -1.33 & 8 & $<.025$ \\
\hline & Peggy & 0 & 1.33 & -1.33 & & \\
\hline \multirow[t]{3}{*}{ Thelma } & & 4 & 1.33 & 2.67 & & \\
\hline & Peggy & 0 & 1.33 & -1.33 & 8 & $<.025$ \\
\hline & Pampy & 0 & 1.33 & -1.33 & & \\
\hline
\end{tabular}


TABLE VI

OBSERVED COPULATIONS WITHIN PAIRS OF FEMALES WHERE THE PREFERRED FEMALE WAS LESS HORMONALIY (SEXUALLY) ATTRACTIVE THAN THE NONPREFERRED FEMALE

\begin{tabular}{|c|c|c|c|c|c|c|}
\hline $\begin{array}{l}\text { Preferred } \\
\text { female }\end{array}$ & $\begin{array}{l}\text { non- } \\
\text { preferred } \\
\text { female }\end{array}$ & $\begin{array}{c}\text { \# } \\
\text { observed } \\
\text { cop.s }\end{array}$ & $\begin{array}{c}\text { \# } \\
\text { cop.s } \\
\text { expected }\end{array}$ & o-e & $x^{2}$ & $P$ \\
\hline \multirow[t]{2}{*}{ Thelma } & & 8 & 4 & 4 & 8 & $<005$ \\
\hline & Peggy & 0 & 4 & -4 & & \\
\hline \multirow[t]{2}{*}{ Thelma } & & 1 & .5 & .5 & 1 & $<.500$ \\
\hline & Wendy & 0 & .5 & -.5 & & \\
\hline
\end{tabular}


TABLE VII

OBSERVED COPULATIONS WITHIN TRIOS OF FEMALES WHERE THE PREFERRED FEMALE WAS LESS HORMONALLY (SEXUALLY) ATTRACTIVE THAN THE NONPREFERRED FEMALES

\begin{tabular}{|c|c|c|c|c|c|c|}
\hline $\begin{array}{l}\text { Preferred } \\
\text { female }\end{array}$ & $\begin{array}{c}\text { non- } \\
\text { preferred } \\
\text { females }\end{array}$ & $\begin{array}{c}\text { \# } \\
\text { observed } \\
\text { cop.s }\end{array}$ & $\begin{array}{c}\text { 非 } \\
\text { cop.s } \\
\text { expected }\end{array}$ & $0-e$ & $x^{2}$ & $P$ \\
\hline \multirow[t]{3}{*}{ The Ima } & & 1 & .33 & .67 & & \\
\hline & Peggy & 0 & .33 & -.33 & 2 & $<.500$ \\
\hline & Carrie & 0 & .33 & -.33 & & \\
\hline \multirow[t]{3}{*}{ Thelma } & & 3 & 1 & 2 & & \\
\hline & Peggy & 0 & 1 & -1 & 6 & $<.050$ \\
\hline & Pampy & 0 & 1 & -1 & & \\
\hline \multirow[t]{3}{*}{ Wendy } & & 3 & 1 & 2 & & \\
\hline & Carolyn & 0 & 1 & -1 & 6 & $<.050$ \\
\hline & Peggy & 0 & 1 & -1 & & \\
\hline \multirow[t]{3}{*}{ Thelma } & & 2 & .67 & 1.34 & & \\
\hline & Peggy & 0 & .67 & -.67 & 4 & $<.250$ \\
\hline & Wendy & 0 & .67 & -.67 & & \\
\hline
\end{tabular}




\section{TABLE VIII}

NUMBER OF THRUSTS TO EJACULATIONS BY PAN WITH THE FEMALES

DURING VARIOUS LEVELS OF TURGIDITY/ATTRACTIVENESS

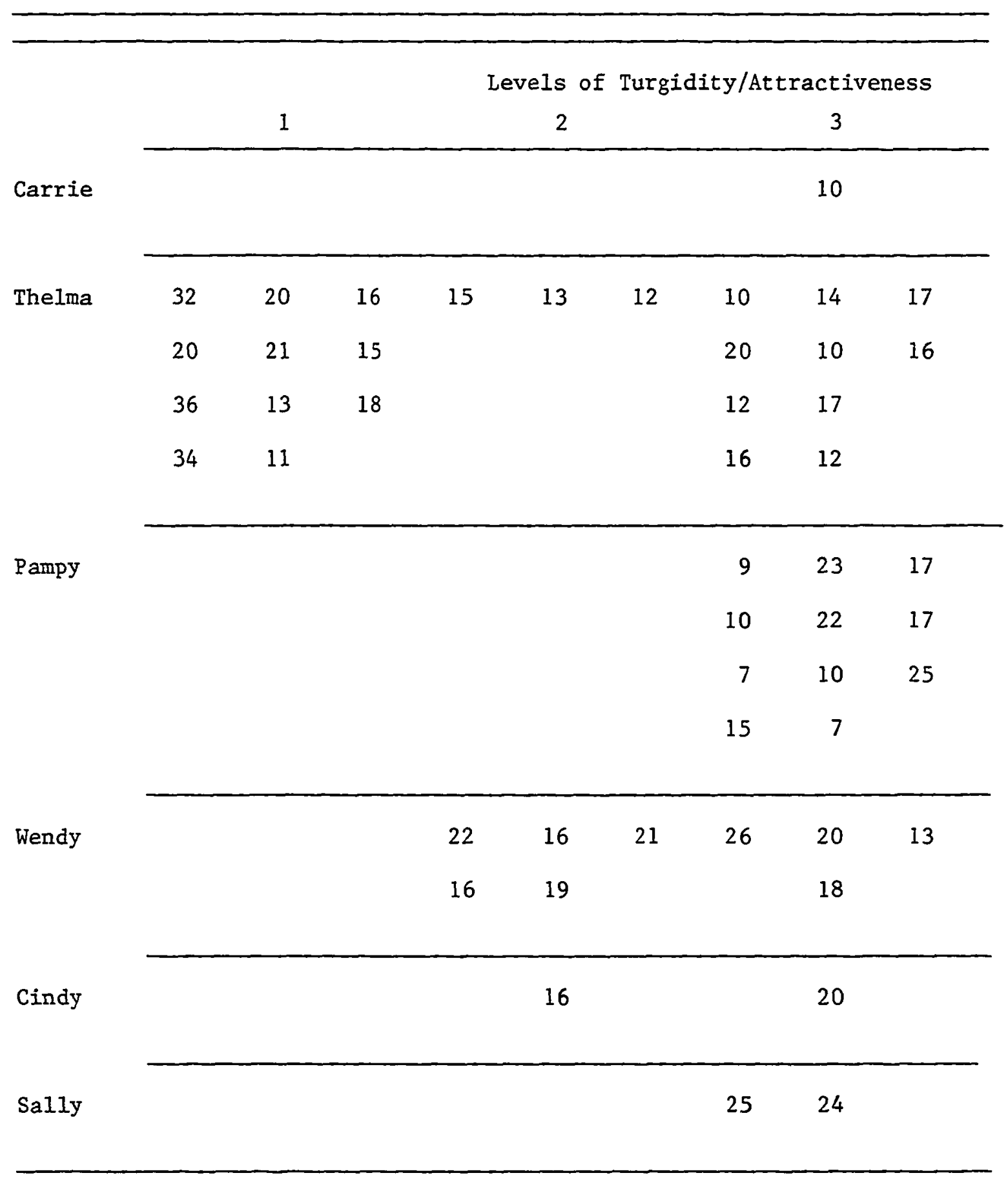

Note: Total thrusts were not visible for 15 copulations. 


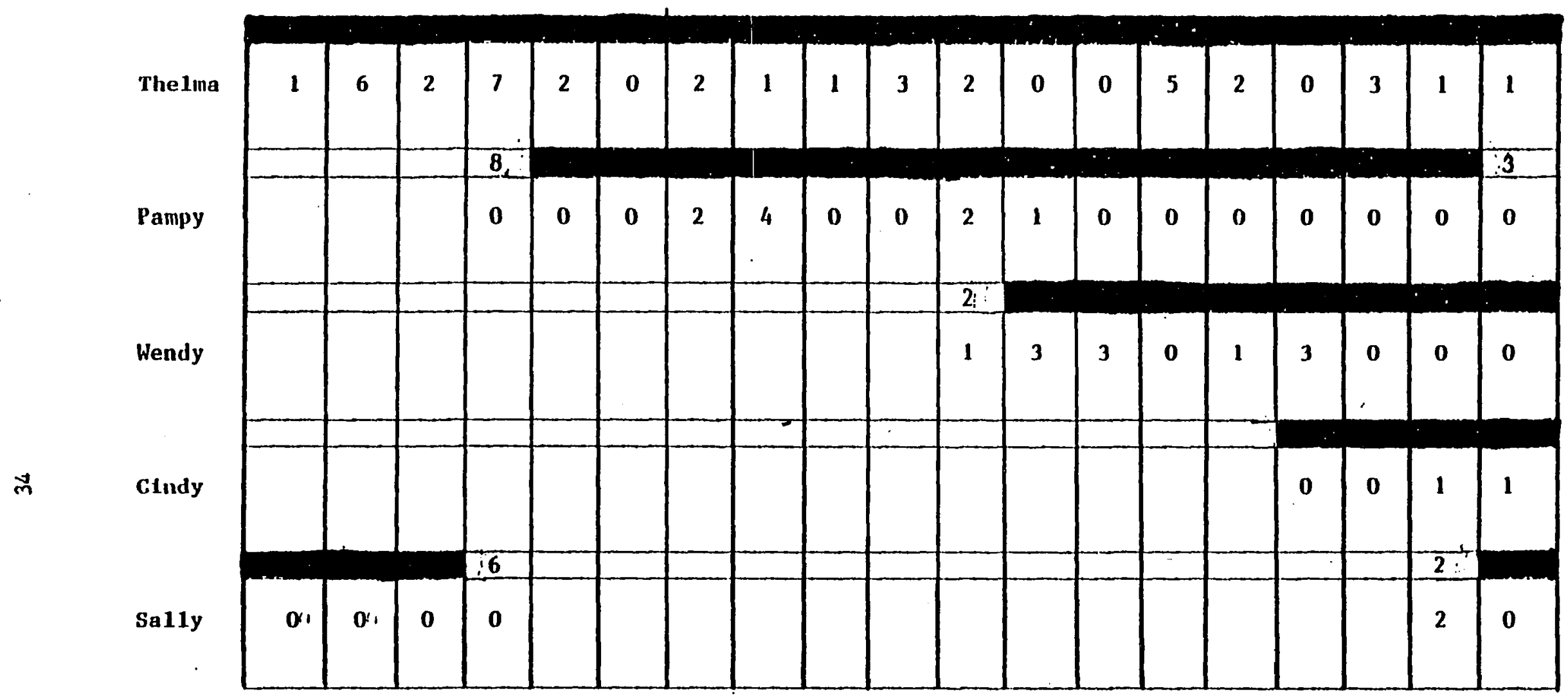

Fig. 1. Observed copulations in complete and partial 10-day blocks. Horizontal bars represent continuous days of avallability with Pan. Numerals lateral to the horizontal bars represent continuous days of avallabilty within a 10-day block. The f1rst 4 days of data are excluded. 


\section{REFERENCES}

Agar, M. E. and Mitchell, G. (1975). Behavior of free-ranging rhesus macaques: a review. Pp. 323-342 in The rhesus monkey, vo1. 1, G. H. Bourne (ed.), Academic Press, New York.

Allen, M. L. and Lemmon, W. B. (in preparation). Orgasm in female primates.

Ball, J. (1941). Effect of progesterone on sexual excitability in the female monkey. Psychol. Bull. 38: 533-534.

Beach, F. A. (1976a). Hormonal control of sex-related behavior. Pp. 247-267 in Human sexuality in four perspectives, F. A. Beach (ed.), Johns Hopkins University Press, Baltimore.

Beach, F. A. (1976b). Sexual attractivity, proceptivity, and receptivity in female mammals. Horm. Behav. 7: 105-138.

Coe, C. L.: Connolly, A. C.: Kraemer, H. C. and Levine, S. (1979). Reproductive development and behavior of captive female chimpanzees. Primates 20: 571-582.

Dixson, A. F.; Everitt, B. J.; Herbert, J.; Rugman, S. M. and Scruton, D. M. (1973). Hormonal and other determinants of sexual attractiveness and receptivity in rhesus and talapoin monkeys. Pp. 36-63 in IVth Int. Congr. Primato1., vol. 2: Primate Reproductive Behavior, Karger, Basel.

Eaton, G. G. and Resko, J. A. (1974). Ovarian hormones and sexual behavior in Macaca nemestrina. J. Comp. Physiol. Psychol. 86: 919-925. 
Enomoto, T. (1974). The sexual behavior of Japanese monkeys. J. Hum. Evol. 3: $351-372$.

Enomoto, T. (1978). On social preference in sexual behavior in Japanese monkeys (Macaca fuscata). J. Hum. Evol. I: 283-293.

Everitt, B. J. and Herbert, J. (1969). The role of ovarian hormones in the sexual behavior of thesus monkeys. Anim. Behav. 17: 738-746.

Ford, C. S. and Beach, F. A. (1951). Patterns of sexual behavior. Harper and Row, New York.

Fox, C. A. and Fox, B. (1971). A comparative study of coital physiology, with special reference to the sexual climax. I. Reprod. Fertil. 24: 319-336.

Goldfoot, D. A. (1971). Hormonal and social determinants of sexual behavior in pigtail monkeys (Macaca nemestrina). Pp. 325-341 in Normal and abnormal development of brain and behavior, G. B. A. Stoelinga and J. J. van der Terff ten Bosch (eds.), Leiden University Press, Leiden.

Goodall, J. (1965). Chimpanzees of the Gombe Stream. Pp. 425-473 in Primate behavior: field studies of monkevs and apes, I. Devore (ed.), Holt, Rinehart and Winston, New York.

Graham, C. E. (1970). Reproductive physiology of the chimpanzee. Pp. 183-220 in The chimpanzee, vol. 3, G. H. Bourne (ed.), Karger, Basel. Graham, C. D.; Collins, D. C.; Robinson, B. and Preedy, J. R. K. (1972). Urinary levels of estrogens and pregnanediol and plasma leveis of progesterone during the menstrual cycle of the chimpanzee: relationship to the sexual swelling. Endocrinol. 91: 13-24. 
Graham, C. E. (1973). Chimpanzee endometrium and sexual swelling during menstrual cycle or homone administration. Folia Primatol. 19: 458-468.

Graham, C. E. (1976). The chimpanzee: a unique model for human reproduction. Pp. 29-38 in The laboratory animal in the study of reproduction, Th. Antikalzides, I. Ericksen and A. Spiegel (eds.), Gustav, Fischer, Verlag, New York.

Hausfater, G. (1975). Dominance and reporduction in baboons (Papio cynocephalus). Contrib. Primatol. 7: 1-150.

Hays, W. L. (1973). Statistics for the social sciences, 2nd ed. Holt, Rinehart and Winston, New York.

Herbert, J. (1968). Sexual preference in the rhesus monkey Macaca mulatta in the laboratory. Anim. Behav. 16: 120-128.

Herbert, J. (1978). Neurohormonal integration of sexual behaviour in female primates. Pp. 467-491 in Biological determinants of sexual behaviour, J. B. Hutchison (ed.), John Wiley and Sons, New York. Hess, J. P. (1973). Some observation on the sexual behavior of captive lowland gorillas, Gorilla g. gorilla (Savage and Wyman). Pp. 508581 in Comparative ecology and behaviour of primates, R. P. Michael and J. H. Crook (eds.), Academic Press, New York.

Hobson, W.: Coulson, F.; Faiman, C.; Winter, J. S. D. and Reyes, F. (1976). Reproductive endocrinology of the female chimpanzee: a suitable model for humans. J. Tox. Environ. Hlth. 1: 657-668.

Kinsey, A. C.; Pomeroy, W. B.; Martin, C. E. and Gebhard, P. H. (1953). Sexual behavior in the human female. Ti. B. Saunders, Philadelphia. 
Kummer, H. (1971). Primate societies: group techniques of ecological adaptation. Aldine, New York.

Kortlandt, A. (1962). Chimpanzees in the wild. Sci. Amer. 206: 128-138. Lancaster, J. B. (1979). Sex and gender in evolutionary perspective. Pp. 51-80 in Human sexuality: a comparative and developmental perspective, H. A. Katchadourian (ed.), University of California Press, Berkeley.

Iaxick-Goodall, J. van. (1975). The behaviour of the chimpanzee. Pp. 56100 in Hominisation and Verhalten, I. Eibl-Eibesfeldt (ed.), Gustav, Fischer, New York.

Lemmon, W. B. and Allen, M. L. (1978). Continual sexual receptivity in the female chimpanzee (Pan troglodytes). Folia Primatol. 30: 80-88. McGinnis, P. R. (19.73). Patterns of sexual behavior in a community of free living chimpanzees. Ph.D. thesus, University of Cambridge. Michael, R. P. (1968). Gonadal hormones and the control of primate behavior. Pp. 69-93 in Endocrinology and human behavior, R. P. Michael (ed.), Oxford University Press, New York.

Michael, R. P.; Keverne, E. B. and Bonsall, R. W. (1971). Pheromones: isolation of male sex attractants from a female primate. Science 172: 964-966.

Michael, R. P.; Zumpe, D.; Keverne, E. B. and Bonsall, R. W. (1972). Neuroendocrine factors in the control of primate behavior. Rec. Prog. Horm. Res. 28: 665-706.

Money, J.: Hampson, J. G. and Hampson, J. L. (1957). Imprinting and the establishment of gender role. A. M. A. Arch. Neuro1. 또 Psychiat. 77: $333-336$. 
Money, J. (1961). Sex hormones and other variables in human eroticism. Pp. 1383-1400 in Sex and internal secretions, vol. 2. 3rd ed., W. C. Young (ed.), Williams and Wilkins, Baltimore.

Nishida, T. (1968). The social group of wild chimpanzees in the Mahali Mountains. Primates 9: 167-224.

Perachio, A. A.; Alexander, M. and Marr, L. D. (1973). Hormonal and social factors affecting evoked sexual behavior in rhesus monkeys. Amer. J. Phys. Anthropol. 38: 227-232.

Phoenix, C. H. (1973). Ejaculation by male rhesus as a function of the female partner. Horm. Behav. 4: 365-370.

Pusey, A. (1979). Inter-community transfer of chimpanzees in the Gombe National Park. Pp. 465-479 in The great apes: perspectives on human evolution, vol. 5, D. A. Hamburg and E. R. McCown (eds.), Benjamin/Cummings, Menlo Park, California.

Rowel1, T. E. (1963). Behaviour and female reproductive cycles of rhesus macaques. I. Reprod. Fertil. 6: 193-203.

Sayman, G. S. (1970). The menstrual cycle and sexual behavior in a troop of free-ranging chacma baboons (Papio ursinus). Folia Primatol. 12: $81-110$.

Saayman, G. S. (1972). Effects of ovarian hormones upon the sexual skin and mounting behavior in the free-ranging chacma baboon (Papio ursinus). Folia Primatol. 17: 297-303.

Slob, A. K.; Baum, M. J. and Schenck, P. E. (1978a). Effects of the menstrual cycle, social grouping, and exogenous progesterone on the heterosexual interaction in laboratory housed stumptail macaques (Macaca arctoides). Physiol. \& Behav. 21: 915-921. 
Slob, A. K.; Wiegand, S. J.; Goy, R. W. and Robinson, J. A. (1978b). Heterosexual interactions in laboratory-housed stumptail macaques (Macaca arctoides): observations during the menstrual cycle and after ovariectomy. Horm. Behav. 10: 193-211.

Stephenson, G. R. (1975). Social structure of mating activity in Japanese macaques. Pp. 63-115 in Proceedings from the Symposia of the 5 th Congress of the International Primatological Society, S. Kondo, M. Kawai, A. Ehara and S. Kawamura (eds.), Japanese Science Press, Tokyo.

Tutin, C. E. G. (1975). Exceptions to promiscuity in a feral chimpanzee community. Pp. 445-449 in Contemporary Primatology, S. Kondo, M. Kawai, and A. Ehara (eds.), Karger, Basel.

Tutin, C. E. G. (1979). Mating patterns and reproductive strategies in a community of wild chimpanzees (Pan troglodytes schweinfurthii). Behav. Ecol. Sociobiol. 6: 29-38.

Tutin, C. E. G. and McGinnis, P. R. (in press). Reproduction of the chimpanzee in the wild. In Reproductive biology of the great apes, D. E. Graham (ed.), Academic Press, New York.

Wickler, W. (1967). Socio-sexual signals and their intraspecific imitation among primates. Pp. 69-147 in Primate ethology, D. Morris (ed.), Weidenfeld and Nicholson, London.

Wolfe, L. (1979). Behavioral patterns of estrous females of the Arashiyama West troop of Japanese macaques (Macaca fuscata). Primates 20: 525-534.

Wrangham, R. W. (1979). Sex differences in chimpanzee dispersion. Pp. 481-489 in The great apes: perspectives on human evolution, vol. 5, D. A. Hamburg and E. R. McCown (eds.), Benjamin/Cummings, Menlo Park, California 
Young, W. C. and Orbison, W. D. (1944). Changes in selected features of behavior in pairs of oppositely sexed chimpanzees during the sexual cycle and after ovariectomy. J. Comp. Physiol. Psychol. 37: $107-143$.

Yourg, W. C. (1961). The hormones and mating behavior. Pp. 1173-1239 in Sex and internal secretions, vol. 2, 3rd ed., W. C. Young (ed.), Williams and Wilkins, Baltimore. 